doi $\underline{\mathrm{http}: / / \mathrm{dx} . \text { doi.org/10.18542/rmi.v15i24.10087 }}$

Margens: Revista Interdisciplinar | e-ISSN:1982-5374 | V. 15 | N. 24 | Jun, 2021, pp. 47-59.

\title{
GESTÃO DOS CORPOS NAS FAVELAS E PERIFERIAS NO RIO DE JANEIRO: DAS
} REMOÇÕES À COVID-19

\section{MANAGEMENT OF BODIES IN FAVELAS AND PERIPHERIES IN RIO DE JANEIRO: FROM REMOVALS TO COVID-19}

Flávio ROCHA (UERJ) $)^{1}$

\begin{abstract}
Resumo: No decorrer da república brasileira, as favelas e periferias foram alvos de diversas intervenções da administração pública. Estes lugares foram sempre colocados como "o outro", como vulneráveis, como "problemas". Esses problemas, no ponto de vista estatal, devem sofrer intervenções, seja através de remoções, de militarizações, do mercado imobiliário, entre outras distintas maneiras de se gerir determinada população. Ou simplesmente, pode ser deixada a mercê de uma precarização proposital em um momento de crise. Portanto, o presente estudo utilizará a cidade do Rio de Janeiro como estudo de caso para exemplificar os diferentes processos de produção e gestão de áreas de periferização em contextos urbanos.
\end{abstract}

Palavras-chave: Remoções, favelas, Covid-19, Gestão, Estado.

\begin{abstract}
In the course of the Brazilian Republic, the favelas and peripheries were the targets of several public administration interventions. These places were always placed as "the other", as vulnerable, as "problems". From a state point of view, these problems must be addressed through removals, militarization, the real estate market, among other different ways of managing a given population. Or simply, it can be left at the mercy of a purposeful precariousness in a time of crisis. Therefore, this study will use the city of Rio de Janeiro as a case study to exemplify the different production and management.
\end{abstract}

Keywords: removals, favelas, Covid-19, management, State

\footnotetext{
${ }^{1}$ Mestrando em Ciências Sociais pelo Programa de Pós-Graduação em Ciências Sociais (PPCIS/UERJ). Atua como professor de Sociologia na rede privada de ensino, nas modalidades Ensino Médio e Pré-Vestibular. Também contribui como professor voluntário de Sociologia e orientador pedagógico, com experiência de quatro anos em pré-vestibulares comunitários. E-mail: flavio.rps@gmail.com
} 


\section{INTRODUÇÃO}

O presente artigo busca expor os aprendizados obtidos a partir de alguns dos encontros da disciplina "Conflitos e periferias", organizada no segundo semestre de 2020 pelo Observatório Fluminense/UFRRJ e Distúrbio/UERJ, ambos núcleos focados em problemas de pesquisa nos espaços urbanos e rurais. A disciplina foi realizada em meio à pandemia da Covid-19, doença causada pelo coronavírus, que fez com que os encontros fossem todos remotos, demandando adaptação a este novo modelo que proporcionou também alguns contratempos para alguns estudantes, devido às desigualdades na distribuição dos serviços de 'internet' no estado do Rio de Janeiro. Principalmente nas zonas rurais e nos territórios de favelas, áreas que se fazem tão caras para os pesquisadores presentes em nossos debates.

Por outro lado, esse novo modelo possibilitou algo que seria muito difícil, ou diríamos impossível. Que foi trazer professores e pesquisadores de diferentes instituições do Brasil, enriquecendo as reflexões dos estudantes que participaram das aulas nesse semestre. Neste texto dou destaque às exposições do prof. Dr. Alexandre Magalhães (UFRGS), seguida de contribuições da apresentação de Maria Júlia Miranda (Defensoria Pública do Estado do Rio de Janeiro) e Isaías Bezerra de Araújo - Conselho Tutelar do Rio de Janeiro. Além de utilizar as contribuições do trabalho etnográfico da Prof. Dra. Adriana Fernandes (PPCIS/UERJ).

Buscarei relacionar as favelas, periferias e os corpos que residem nessas áreas como alvos de ações do Estado do decorrer do século XX e XXI. Primeiro, as favelas como um problema moral e sanitário que precisava ser removido (início do Séc. XX), segundo, as favelas e áreas como problemas a serem sanados em prol dos megaeventos (2012 - 2016) e, por último, as favelas e periferias como alvos de precarização no contexto da Covid-19 (atual).

Utilizarei das contribuições bibliográficas dos professores presentes, assim como as escutas dos relatos feitos à Defensoria Pública do Estado do Rio de Janeiro. A construção narrativa ocorre com base nas anotações dos encontros, de leituras anteriores sobre estudos urbanos e notícias de jornais relacionadas à pandemia da Covid-19 no Brasil.

\section{OS PRIMEIROS PASSOS DAS REMOÇÕES DE FAVELAS NO RIO DE JANEIRO: PROBLEMA SANITÁRIO A SER ERRADICADO}

Começarei trazendo ao debate o tema das remoções de favelas, que foi abordado na apresentação do professor Alexandre Magalhães e é sempre muito bem abordado em seus trabalhos 
acadêmicos (2013, 2018, 2019). Desde os acontecimentos mais antigos que abrangem o início do século XX até os dias atuais com os megaeventos e megaempreendimentos, sempre buscando sobrevalorizar as regiões em detrimento da proletarização e precarização de outras, produzindo sempre novos vazios e apagando diversas histórias nas cidades contemporâneas.

Neste sentido, vale fazer uma breve digressão em como essa prática esteve presente na construção política do Rio de Janeiro, em que através de distintas práticas estatais buscou fixar pessoas em territórios específicos, sempre afastando dos grandes centros econômicos e centrais da cidade, produzindo periferias e áreas nobres. Definindo assim as margens no solo fluminense.

Entre 1902 e 1906 no Rio de Janeiro o prefeito de Pereira Passos, conhecido como um dos principais "reformadores" da cidade, entre seus feitos em destaque está a construção da Avenida Central (hoje Av. Rio branco) ${ }^{2}$, remoção do cortiço Cabeça de porco, e demais reformas no Centro. Essas políticas eram carregadas pelo discurso da saúde pública, pois as ruas desta localidade eram estreitas, escuras e sujas, e contavam com habitações precárias, coletivas e com pouca higiene.

O movimento de retirada dos cortiços e demais moradias na área central, fez com que diversas famílias iniciassem migrações para o subúrbio, baixada e para os morros. Desta forma iniciava-se a tradição de reformas urbanas que geravam a expulsão de populações negras e pobres para as áreas que tornar-se-iam periféricas.

Sendo assim a partir da década de 1930, a ideia de favela começa a ser reconhecida pelo Estado, do mesmo modo, estas "seriam tratadas, inicialmente, como um "câncer" que deveria ser extirpado do espaço da cidade, dado que sua existência representaria um "elemento disruptivo" da sociedade e apresentaria uma ameaça ao restante da metrópole (MAGALHÃES, 2013, pp. 38-39). Os engenheiros e sanitaristas ganharam um protagonismo na época, figuras como Oswaldo Cruz e Francisco Bicalho entraram em cena com o intuito de "higienizar" esses que eram considerados locais insalubres dentro da capital federal.

Magalhães (2013) também demarca um segundo momento na década de 1930, no período do governo de Getúlio Vargas. Em que os mais pobres, moradores de favelas não seriam somente repreendidos, mas passariam por um "trabalho pedagógico de civilização". "A habitação passaria a compor este repertório, como importante elemento estruturante desta transformação do pobre em trabalhador” (MAGALHÃES, 2013, p. 40), surgem então as moradias populares como uma nova forma de "civilizar" essas populações, enquanto as favelas tornavam-se ilegais e um sinônimos de

${ }^{2}$ Neste mesmo período ocorreu a remoção do Morro do Castelo, iniciada por Pereira Passos e continuada por Carlos Sampaio em 1921. 
insalubridade e imoralidade, oposto do progresso e da civilização, portanto, os trabalhadores não poderiam conviver nesses locais.

O período do Estado Novo, em 1945, foi marcado pelo surgimento dos parques proletários e uma continuidade do discurso contrário às favelas, principalmente nos meios jornalísticos, onde figurava Carlos Lacerda, personagem que travou uma verdadeira guerra contra esses territórios, principalmente a partir de 1960, ano em que tomou posse do recém-criado Estado da Guanabara ${ }^{3}$. Lacerda em seus discursos dizia que as favelas não eram mais um problema localizado nem habitacional, mas era um obstáculo que atingia as dimensões sociais, psicológicas, sanitárias e educacionais (CASTRO, 2004).

Iniciou-se aí o período de remoções, ao mesmo tempo, em que os governos estavam preocupados com a "higienização" dos bairros mais ricos, também estavam com o intuito de fixar os mais pobres em uma área mais distante do Centro e da Zona Sul da cidade, além de criar uma região proletarizada. De onde vinha acentuando-se um processo de industrialização, somado com a construção da Avenida Brasil e ao loteamento da Zona Oeste. Esse processo de fixação tem o intuito também de classificar e hierarquizar e pessoas em territórios, a partir de fixações na cidade através de políticas públicas. Castro (2004) também diz que há três momentos de percepção sobre "favelados" e seus locais de moradia, o primeiro, busca identificar e erradicar as favelas, o segundo tenta organizálas, e a terceira tem o objetivo de integrá-lo em uma organização urbana.

Dessa forma surgiam os Conjuntos Habitacionais (FARIAS, 2011), durante Governo do Estado da Guanabara ${ }^{4}$ (década de 1960) com o surgimento da COHAB (Cooperativa de Habitação Popular) para construir casas para os moradores removidos das favelas na Zona Sul. Surgindo então as comunidades da Vila Kennedy, Vila Aliança, Senador Camará, Vila Esperança, entre outras; que abrigou em torno de 37 mil habitantes que moravam nas áreas removidas. As remoções perduraram nos governos estaduais de Carlos Lacerda (1961 - 1965), Negrão de Lima (1965 - 1970) e Chagas Freitas (1970 - 1975).

Outras políticas habitacionais de fixação de pessoas nas áreas periferizadas da cidade continuaram com o primeiro governo de Leonel Brizola (1983 - 1987) através da Companhia de

\footnotetext{
${ }^{3}$ Quando a capital do Brasil passou para Brasília, a atual cidade do Rio de Janeiro passou a ser considerada Estado da Guanabara (1960 a 1975).

${ }^{4}$ A cidade do Rio de Janeiro, entre 1960 e 1970 era o Estado da Guanabara, independente do Estado do Rio de Janeiro. Esta separação ocorreu quando a cidade do Rio de Janeiro deixou de ser o distrito federal e a capital do país se tornou Brasília.
} 
Habitação popular do Estado do Rio Janeiro (CEHAB-RJ), com o programa Cada Família, um Lote , casas para populações de baixa renda principalmente na Zona Oeste da cidade do Rio de Janeiro.

Em âmbito municipal, as prefeituras de César Maia (1993 - 1997/2001 - 2009) e Luiz Paulo Conde (1997 - 2001) elaboraram as políticas habitacionais Rio Cidade e Favela bairro, esses programas em específico, com recursos da prefeitura do Rio e do BID (Banco Interamericano de Desenvolvimento) buscava, uma "integração" das favelas com a cidade. Isso ocorreria através da regularização de loteamentos; educação sanitária e ambiental e urbanização de favelas onde se inseriu o Programa Favela-Bairro, com a maior parte dos recursos: US \$192 milhões (CORREIA, 2006). Essas políticas ficaram conhecidas pela participação das associações de moradores que se posicionavam e tinham suas demandas consideradas em partes do processo.

Vemos nesse primeiro momento que ocorre uma transformação na favela que deixa de ser um problema sanitário e passa a ser um problema infraestrutura, social e urbano. Deixa de ser alvo de remoções com o objetivo de erradicá-las e torna-se um elemento passível de integração ao tecido urbano do Rio de Janeiro. Portanto, isso não serviu para todos os territórios e nem sequer significava o fim das remoções na capital fluminense, surgiriam novos episódios e novos motivos para tais práticas.

\section{AS REMOÇÕES E A RELAÇÃO COM OS MEGAEVENTOS E A ESPECULAÇÃO IMOBILIÁRIA: GESTÃO DE CORPOS NO RIO OLÍMPICO}

Discípulo do ex-prefeito César Maia, Eduardo Paes foi eleito em uma disputa apertada nas eleições de 2008, com 50,83\% dos votos. Assim como seu padrinho político, seguiu nas intervenções urbanas do Rio de Janeiro, só que dessa vez por via das remoções das favelas, modelo de intervenção que não era visto da capital há algumas décadas ${ }^{6}$. Houve diversas justificativas para isso, por "riscos" de desabamento de casas localizadas em partes altas de morro ou beiras de rios, ou ocuparem áreas ambientais, ou pelo "legado olímpico" que deveria ser construído pelas próximas gestões.

Salienta-se que, Paes, assim como Lacerda, declarava guerra aos territórios favelados.

\footnotetext{
${ }^{5}$ Nela pretendia-se regularizar 400 mil lotes clandestinos, dotando a área a ser afetada de significativa urbanização. Nessa época, a política habitacional sofre uma ruptura: o remocionismo foi abolido do discurso oficial e o governo trouxe para si a questão fundiária; o Programa Cada Família, um Lote foi o grande destaque desta nova postura ao trazer postulados como: regularização fundiária, melhorias urbanas, manutenção da população na própria comunidade, dentre outras (CORREIA, 2006).

${ }^{6}$ Estima-se que, entre 2009 e 2014, quase 22 mil famílias tenham sido removidas de suas casas (MAGALHÃES, 2018). 
Produzia-se novamente a ideia de favela enquanto "espaço da desordem que precisa ser eliminado ou controlado" (MAGALHÃES, 2018, p. 4). Magalhães (2018) analisa que, as experiências de vida destas populações se configuravam com base em um tensionamento constante por parte dos aparatos estatais, e dessa forma, gerava-se um cenário de guerra, pois via-se vestígios de destruição, inexistência e terror.

Novamente a administração pública buscava fixar pessoas em lugares específicos, dessa vez a partir dos interesses olímpicos e imobiliários. Ou seja, já que a prefeitura reivindicava locais que seriam úteis para o mercado imobiliário, precisava-se retirar as populações indesejáveis desses locais rentáveis ao mercado, e dessa forma, valorizar determinada região para produzir os empreendimentos habitacionais de uma classe alta, ou equipamentos olímpicos. Esse grupo "indesejado" pela prefeitura seria movido, através das remoções, para áreas periferizadas da cidade ou para abrigos. Geralmente essas regiões não somente eram distantes das áreas valorizadas, mas também eram em condomínios residenciais - com vários problemas estruturais - construídos pela gestão municipal.

diferentes dimensões e questões relacionadas a distintos espaços e lugares da cidade são tratadas como uma 'guerra' a ser travada pelas forças instituídas contra o que é definido como potencial 'risco’ à ordem urbana (e também dos negócios) [...] Nestes casos de remoção, em inúmeras ocasiões, os moradores tiveram que lidar com o uso de grandes aparatos de segurança, notadamente formados pela Guarda Municipal (MAGALHÃES, 2018, p. 6).

Segundo Magalhães (2018) as políticas remocionistas operam não somente em uma lógica de guerra e destruição, mas também de terror. Através da cena dos entulhos, ferros retorcidos e restos de um local onde se produziu memórias, afetos e vivências, o Estado demonstra a sua força, descaracteriza $^{7}$ um espaço em prol de um outro a ser produzido em nome de um desenvolvimento, uma lógica perversa que tem sempre um preço a ser pago. "Esses 'atos de destruição' implicavam à reorientação das trajetórias locais cotidianas, haja vista necessidade de agora, ter que levar em consideração o novo cenário" (MAGALHÃES, 2018, p. 10).

Essa reorientação se dava através da obrigação dos moradores removidos a viver em outro local da cidade, para territórios vistos como 'distantes'. No caso dos moradores da favela MetrôMangueira, mencionada pelo autor no texto, seriam levados para o bairro de Cosmos, Zona Oeste do Rio de Janeiro. Nesse exemplo, vejo novamente a Zona Oeste da cidade sendo um local de

${ }^{7} \mathrm{O}$ autor destaca que essa prática ocorria durante o processo de negociação dos moradores com a prefeitura, até mesmo após a aceitação de uma nova unidade habitacional. As construções nas favelas não eram totalmente demolidas imediatamente, somente algumas de suas partes, sendo abertos buracos na laje e nas paredes. Isso ocorria como forma de pressão da administração pública para que as propostas fossem aceitas pelos moradores. 
periferização, um local de fixação de corpos negros, pobres e 'indesejáveis' aos olhos do Estado. Afinal, não era benéfica para a Copa do Mundo e ao Legado Olímpico a existência de favelas nas proximidades de um grande palco como o Estádio Maracanã. Era necessário, segundo Magalhães (2018, p. 12), "a limpeza de um dado cenário para ali produzir novos fluxos".

Em síntese, narra-se aqui dois momentos de fixação e de olhares sobre as favelas no Rio de Janeiro. O primeiro colocando a favela como um problema sanitário e moral, o segundo trazendo a favela como um espaço de atraso aos megaeventos e à especulação imobiliária. Vimos aqui um cenário de transformação na postura do Estado frente às favelas e territórios periféricos. Por fim, vale trazer a gestão dessas populações no atual cenário da pandemia da COVID-19, um contexto em que a retórica sanitária ganha uma nova vestimenta, no entanto, utiliza-se uma nova forma de gestão.

\section{UM NOVO PROBLEMA SANITÁRIO. A GESTÃO DA COVID-19 E OS REFLEXOS NAS} FAVELAS DO RIO DE JANEIRO

Em 2020 fomos surpreendidos pela pandemia do coronavírus, iniciada em março impondo regras de isolamento social em diversas instâncias da vida cotidiana. Aulas em creches, escolas, prévestibulares e universidades foram interrompidas, muitos comércios foram fechados, eventos públicos que já estavam agendados foram suspensos, causando consequências na empregabilidade e impactando a renda de muitas pessoas. Isso fez com que até a militância política se reorganizasse na mobilização, fazendo com que novas formas de articulação se desenhassem neste cenário que alguns setores da sociedade começaram a denominar como "o novo normal".

Com a crise declarada na economia que causou aumento no desemprego. Muitas pessoas nas áreas periferizadas começaram a passar por necessidades, diariamente mostrava-se nos telejornais ${ }^{8}$, as comunidades, favelas, pessoas pobres passando por dificuldades, faltando o básico para se alimentar e para exercer a higiene pessoal como forma de prevenção ao coronavírus, através da higienização das superfícies do corpo e dos objetos.

Magalhães (2020) traz à tona a dificuldade da realização do isolamento social nessas localidades. Considerada a principal medida de prevenção à Covid-19, esta tornou-se privilégio das classes mais altas. $\mathrm{Na}$ medida que, as favelas, em sua grande maioria, consistem em locais

\footnotetext{
${ }^{8}$ Epidemiologistas, pesquisadores da área da saúde, médicas/médicos sanitaristas ocuparam jornais e mídias. E, ainda, jornalistas, economistas e urbanistas projetando as consequências do que se chamou de "distanciamento" e suas modulações quarentena, isolamento, confinamento, lockdown em outras partes do mundo; somados a estes, comentários de especialistas sobre remédios e vacinas que demorariam (FERNANDES, 2020, p. 9).
} 
superpovoados, com ruas estreitas e muitas moradias de poucos cômodos para muitas pessoas. "Há diferenças de geração, classe e gênero, raça e lugar de moradia que demarcam as possibilidades de cuidado e de acesso aos serviços médico-hospitalares (também assistenciais), já que tanto aquelas possibilidades quanto o acesso a estes serviços são distribuídos desigualmente entre as classes e camadas sociais" (MAGALHÃES, 2020, p. 79).

Além da dificuldade de exercer o isolamento, essas áreas da cidade são também vitimadas por um processo de precarização. Que é proposital, produzido por uma lógica de gestão de corpos, que busca fixar grupos de pessoas em espaços precários, escassos de políticas públicas, assistência social e infraestrutura. Na capital do Rio de Janeiro, a gestão Marcelo Crivella (2016 - 2020), foi responsável por diversas produções de precarização na área de saúde, desde a atenção básica até as emergências. Ocorreu demissão de profissionais da saúde, fechamento de clínicas e redução das equipes de saúde primária. O impacto disso já vinha sendo notado ainda nos primeiros anos de mandato e foi escancarado quando chegou a pandemia em 2020.

Dessa forma, a população periferizada e negra foi a que mais sentiu o impacto, considerando o contingente populacional de pretos e pardos nesses territórios. Reforça-se, portanto, uma produção de morte através da negligência de serviços que são fundamentais para a manutenção da vida, ou seja, uma Necropolítica9 . Do mesmo modo, o isolamento social tornou-se uma questão delicada e, também, privilégio dos mais ricos, de algumas classes de trabalhadores formais e funcionários públicos. Visto que, a maioria dos moradores de periferias dependem da circulação pela cidade, são nessas áreas que estão domésticas, vendedores de lojas, camelôs, motoristas de transporte público e de aplicativos, profissionais de saúde, entre outras diversas classes que não deixaram de se expor durante a vigência da doença.

Segundo Fernandes (2020) surge na sociedade uma ideia, aceita por segmentos da sociedade e do governo de que determinados corpos poderiam permanecer mais expostos ao vírus e, por conseguinte, mais expostos à morte. A autora sugere que estes possam ser vistos como corpos do

\footnotetext{
${ }^{9}$ A produção de morte descrita por Achille Mbembe (2016), coloca o racismo como elemento central na distribuição de morte, que recai sobre populações racialmente vulneráveis. "A raça foi a sombra sempre presente sobre o pensamento e a prática das políticas do Ocidente, principalmente quando se trata de imaginar a desumanidade de povos estrangeiros ou dominá-los (MBEMBE, 2016, p. 128). Além disso, a racionalidade da vida passa pela morte do outro; ou que a soberania consista na vontade e capacidade de matar para possibilitar viver. Além disso, a racionalidade da vida passa pela morte do outro; ou que a soberania consista na vontade e capacidade de matar para possibilitar viver. Segundo o autor, "a raça não existe enquanto fato natural físico, antropológico ou genético. Raça não passa de uma ficção útil, de uma construção fantasista ou de uma projeção ideológica cuja função é desviar a atenção de conflitos antigamente entendidos como mais verosímeis - a luta de classes ou a luta de sexos, por exemplo. Em muitos casos, é uma figura autônoma do real, cuja força e densidade podem explicar-se pelo seu caráter extremamente móvel, inconstante e caprichoso (MBEMBE, 2014, p. 27).
} 
sacrifício, vidas sem valor (Agamben, 2002: 145 apud Fernandes, 2020). Podemos enquadrar nesta categoria os trabalhadores formais e informais que tiveram que trabalhar normalmente na pandemia e as pessoas em situação de rua, ambos trabalhados por Fernandes no referido texto. É refletido como alguns grupos de trabalhadores que antes eram invisibilizados, passaram a tornar-se "essenciais", reforçados pela retórica do "novo normal". Podem enquadrar-se nesses grupos, os entregadores de aplicativos, caixas de supermercado, atendentes de farmácias, frentistas, coveiros, faxineiros de hospitais, entre outros; tornam-se "heróis", por se sacrificar, se expor à morte em nome da sobrevivência de toda sociedade.

Relevante mencionar, a questão do transporte público, principal meio de locomoção dos moradores da Baixada Fluminense, Zona Oeste, subúrbio e favelas para seus postos de trabalho. Durante a pandemia, houve uma redução das frotas de ônibus dentro da capital e um aumento do intervalo dos trens urbanos da Supervia - inclusive convertendo o serviço do ramal Santa Cruz que antes era expresso, em parador -, e, por último das barcas que também são fundamentais para a referida população. Deste modo, produziu-se aglomerações dentro dos veículos, aumentando consideravelmente o risco de contágio com o coronavírus.

O perigo à exposição diária ao COVID-19 nos trajetos ao trabalho e a ida às praias, bares e espaços de lazer nas folgas e feriados causou diversas discussões na mídia ${ }^{10}$, nas redes sociais, entre outros espaços. Por um lado, estavam os críticos, abraçados ao discurso puramente epidemiológico, de que as pessoas que estavam indo à praia eram irresponsáveis e que deveriam ficar em casa respeitando o isolamento. Por outro lado, há os que buscam compreender o sentido de classe, visto que, algumas pessoas, trabalhavam diariamente enfrentando transportes públicos lotados, atendimento a variadas pessoas em espaços fechados, optaram, em seu tempo livre, desrespeitar o isolamento para aproveitar a folga. "Se pode aglomerar no transporte, pode aglomerar na praia".

Compreendo que há um meio termo entre as duas argumentações, dado que, a questão epidemiológica deve considerar o lado social da pandemia. Enquanto, o lado social e político também deve respeitar o lado epidemiológico. Ou seja, as medidas de prevenção nos transportes, nos espaços de trabalho e, o principal, a gestão urbana deve adequar-se efetivamente ao novo cenário.

O contingente de transportes deveria ser aumentado, deveria haver lockdown ou maior controle sobre a circulação nos espaços públicos. Ademais, deve-se promover uma renda básica aos

${ }^{10}$ Matéria intitulada: Bate-boca visto ao vivo na GloboNews faz bem ao jornalismo - publicada em: 02/01/2021 https://www.terra.com.br/diversao/tv/blog-sala-de-tv/bate-boca-visto-ao-vivo-na-globonews-faz-bem-aojornalismo,8de63c1aae2c05fe25c42801f67457eblzguhjni.html 
trabalhadores afetados, testagem para a população, higienização constante das ruas, são algumas das medidas que poderiam ser adotadas pelo poder público. Evitando, desse modo, o contágio pelo vírus.

Ainda em relação à pandemia e as periferias, é significativo o documento produzido pela Ouvidoria da Defensoria Pública do Estado do Rio de Janeiro. Denominado "Escuta da sociedade civil sobre combate à pandemia de Covid-19 nas favelas e periferias do Rio de Janeiro"11, o texto elenca onze eixos emergenciais relacionados ao coronavírus nas comunidades. Sendo assim, trago alguns dos eixos para o debate, a fim de refletir sobre outros reflexos da circulação do vírus nas populações mais pobres. O relatório foi elaborado a partir de escutas coletadas entre abril e junho de 2020 e, ouviu "57 lideranças que moram e atuam em favelas e periferias diferentes da Região Metropolitana", além disso, "dentre essas pessoas, $61 \%$ são mulheres e também $61 \%$ são pessoas negras/pretas e pardas".

O primeiro eixo em destaque é o isolamento social, já debatido aqui. Uma vez que, houve dificuldade em aderir o distanciamento de forma plena. $80 \%$ dos entrevistados mencionaram que a medida estava perdendo força e, em todos os relatos foi levantada a questão das condições de moradia, impossibilitando a efetividade da medida. Também foi mencionada a queda no rendimento das famílias das favelas onde os escutados residem. Com isso, ocorreu uma ação do Movimento Unido dos Camelôs para a doação de alimentos para a família de diversos trabalhadores que foram impactadas ao longo da pandemia.

Vale mencionar que, as ações de Coletivos e movimentos sociais em favelas foram essenciais nessa época, reforçando a importância da sociedade civil organizada em diversos contextos, principalmente os de crise. Realizou-se várias campanhas para obter ajuda aos moradores de periferias, entre estas está a campanha Covid-19 nas favelas, organizada pelo "Meu Rio"12. Dou um destaque ao coletivo acompanhado em meu trabalho de dissertação, Coletivo Martha Trindade, que em uma articulação entre movimentos sociais e coletivos dos bairros de Santa Cruz, Sepetiba e Paciência, formou a Coletiva pela Zona Oeste (UCZO) ${ }^{13}$.

Composta por outras 12 (doze) organizações, mobilizou uma benfeitoria ${ }^{14}$ com o intuito de (a) arrecadar doações e comprar alimentos e materiais de higiene, suplentes aos números que seriam atendidos; (b) custear o combustível e meios de locomoção para transportar as doações e a equipe de

11 Veja na íntegra: https://defensoria.rj.def.br/noticia/detalhes/10609-Webinar-apresenta-demandas-das-periferias-napandemia

${ }^{12}$ Veja mais em: COVID19 nas Favelas (meurio.org.br)

${ }^{13}$ Veja mais em: https://www.instagram.com/uczonaoeste/?hl=pt-br

${ }^{14}$ Veja mais em: https://benfeitoria.com/uniaocoletiva 
forma segura; (c) pleitear uma ajuda de custo para parte da equipe que já vinha trabalhando na linha de frente de forma voluntária e que também se encontrava em situação de vulnerabilidade.

Dessa maneira, os grupos buscaram apoio financeiro através de mídias sociais. Mapearam e cadastraram 3.420 (três mil quatrocentas e vinte) famílias que necessitavam de cestas básicas e itens de higiene na região, além de realizar um trabalho de conscientização e ações de prevenção. A arrecadação ocorreu através de uma benfeitoria denominada Matchfounding, uma espécie de "vakinha turbinada", ou seja, a cada R\$ 1 arrecadado o "Fundo Colaborativo Enfrente"15 contribuía com mais R \$2 para atingir o valor final de R \$30 mil.

Em complemento a benfeitoria, Ongs parceiras colaboraram financeiramente para viabilizar as doações, foram elas: Meu Rio, Casa Fluminense e Instituto PACS. Ao fim, 2.899 (duas mil oitocentos e noventa e nove) famílias foram beneficiadas pelas doações, $84 \%$ das que foram cadastradas. E no total foram doadas 4.541 (quatro mil quinhentas e quarenta e uma) cestas básicas com kits de higiene e $56 \%$ das famílias tiveram esse auxílio continuado. Além disso, foram contratados carros de som, faixas elaboradas e a logística da equipe foi viabilizada.

Retornando ao relatório, a Defensoria Pública constatou que houve um aumento das rendas familiares com a pandemia, em consequência, uma sobrecarga ao CRAS, que não conseguia atender integralmente e efetivamente a todos os moradores. $100 \%$ dos escutados tiveram problemas com o auxílio emergencial e, nesse caso, também tiveram a atuação de ONGs e movimentos sociais no apoio aos moradores que tiveram dificuldade em dar entrada no auxílio.

O não funcionamento das escolas, também foi um elemento de grande impacto na vida dessa população. Dado o aumento das despesas familiares em casa com as crianças que ficaram sem a merenda escolar, e pela dificuldade que houve em relação ao acompanhamento do ano letivo. Seja no caso dos estudantes ou dos professores que residem nesses territórios. 39\% dos entrevistados relataram não ter um local adequado para o estudo, enquanto $10 \%$ mencionaram não ter internet. Do total, $89 \%$ disseram não ter sequer recebido o chip de acesso da escola.

Como se não bastasse as dificuldades financeiras, a falta de água, luz e coleta regular de lixo também assolou o cotidiano dos habitantes de periferias. Visto que, a água é um dos elementos mais importantes para higienização e prevenção ao coronavírus e, também se faz necessária para a sobrevivência. Houve relatos de insuficiência na coleta de lixo, poucos equipamentos para depósito, e não chegada da coleta em algumas localidades. Já em relação à energia elétrica, relatou-se a demora no reparo de transformadores queimados nas regiões periféricas.

${ }^{15}$ Responsáveis pelo site da Benfeitoria. 
Por fim, destaco a questão da violência, levantada por dois âmbitos. O primeiro é da violência doméstica, $42 \%$ dos ouvidos relataram ter conhecimento sobre casos de violência doméstica contra crianças durante a pandemia, enquanto $65 \%$ relataram conhecimento de casos de violência doméstica contra mulheres nesse período. Em segundo, a violência de Estado e policial, considerando a vulnerabilidade dessas áreas em relação aos conflitos bélicos, em que há uma constante produção de guerra e morte, em nome de uma falida guerra às drogas.

Dessa forma, $65 \%$ das escutas mencionaram a continuidade das operações policiais, enquanto $35 \%$ dizem não ter ocorrido operações desde o início da pandemia. Importante mencionar que, em junho de 2020, o ministro do STF, Edson Fachin determinou a proibição de operações policiais durante a pandemia. A medida diminuiu significativamente o número de vítimas pela operação policial, chegando à menor marca de letalidade policial do Rio de Janeiro dos últimos quatro anos.

\section{CONCLUSÃO}

Este trabalho nos ajuda a refletir as diferentes formas que o Estado buscou e busca gerir as populações de favelas e periferias - corpos negros em sua maioria. De Pereira Passos à Paes, de Lacerda à Witzel, de Rodrigues Alves à Bolsonaro; as populações desses territórios não tiveram sossego e sempre foram as escolhidas para as diferentes práticas de exclusão, de produção de morte e precarização. Portanto, busquei refletir com ajuda dos autores mobilizados pela disciplina, como as remoções foram produzidas ao decorrer da história do Rio de Janeiro, e quais impactos recaíram sobre os povos periferizados.

Do mesmo modo, a Covid-19 vem à tona para a reflexão, pois, percebemos que essas populações são também as mais atingidas e precarizadas pelas políticas - ou falta delas - em bairros específicos da cidade. O presente artigo é dedicado aos removidos de favelas, aos impactados pelo transporte público carioca, às vítimas da inoperância municipal com a saúde pública e aos acometidos pela Covid-19 no atual momento.

\section{REFERÊNCIAS}

CASTRO, João Paulo. Da favela à comunidade: Formas de classificação e identificação de populações no Rio de Janeiro. Revista Anthropológicas, v. 15, n. 8, 2004, p. 171-198.

CORREIA, Fernanda. Breve Histórico da Questão Habitacional na Cidade do Rio de Janeiro. Revista Eletrônica Achegas, v. 31, set. 2006, p. 31-44. 
FARIAS, Luiz Antonio de. O déficit habitacional na metrópole do Rio de Janeiro: Perfis e contextos. Revista Geográfica da América Central, Número Especial EGAL, 2011, p. 1-16.

FERNANDES, Adriana. Coronel Vírus chegou. Notas etnográficas sobre a Covid-19 entre vulnerabilizados da cidade do Rio de Janeiro. Sexualidad, Salud y Sociedad - Revista Latinoamericana, n. 35, ago. 2020, p. 7-34.

MAGALHÃES, Alexandre. A lógica da destruição: sufocamento, asfixia e resistências nas favelas do Rio de Janeiro. In: LEITE, M. P. et al. (Eds.). Militarização no Rio de Janeiro: da pacificação à intervenção. Coleção Engrenagens Urbanas. Rio de Janeiro: Mórula Editorial, 2018.

MAGALHÃES, Alexandre. Remoções de favelas no Rio de Janeiro: Entre formas de controle e resistências. Curitiba: Appris, 2019.

MAGALHÃES, Alexandre. As periferias na pandemia: explicitação da política de precarização e de exposição à morte. Tessituras: Revista de Antropologia e Arqueologia, v. 8, 2020, p. 79-85.

MAGALHÃES, Alexandre. DE. Transformações no "problema favela" e a reatualização da "remoção" no Rio de Janeiro. Tese de doutorado-Rio de Janeiro: Instituto de Estudos Sociais e Políticos - IESP/UERJ, 2013.

MBEMBE, Achille. Crítica da razão negra. Portugal: Antígona, 2014.

MBEMBE, Achille. Necropolítica. Arte \& Ensaio, n. 32, 2016, pp. 123-151 